\title{
Research on the Influences of Credit Evaluation System on Network Consumption Decisions: Based on Large-scale Data of TMALL
}

\author{
Bin Chen, Lirong Wang* and Mengmin Ye \\ School of Business, Nantong University, Nantong 226019, China \\ Chenbin7776@163.com
}

\begin{abstract}
Network transaction credit evaluation system offer credit basis for online trading, credit information of the products is open to public, in order to solve the problems of the mistrust in e-commerce activities, in some degree, to reduce the e-commerce transaction cost. At the same time, the network credit evaluation system also profoundly affect whether consumers choose online shopping. This paper established econometric model which based on large-scale data of TMALL to analyze the relationship between credit rating system and the commodity sales. Research results show that the total sales and the neutral comments have an obvious influence on the sales of following month; the number of positive and negative comments has an influence on sales of following month; description of the products, service attitude and delivery speed don't have much influence on the sales of following month.
\end{abstract}

Keywords: Credit Evaluation; Consumption Decisions; Network

\section{Introduction}

With the development of e-commerce, online shopping has become a familiar consumption approach. Through the description, pictures and video, consumers can know product attribute and characteristics, such as, the quality of the products, price, packaging and delivery means. Products displayed on line easily stimulate consumer to buy. However, the merchant's credit will decide whether consumers buy the products. In most of the electric business platform, consumers can know every online store from aspect of sales, credibility, and customer satisfaction, which originate from trading credit evaluation system. In the online shopping, credit evaluation system provide online transactions with credit basis, credit information of the products is open to public, in order to solve the problems of the mistrust in e-commerce activities, in some degree, to reduce the e-commerce transaction cost.

With the continuous expansion of the network transaction scale, many scholars began to focus on the influence of credit evaluation system of network e-commerce platform on consumer online shopping decisions. Tokuro Matsuo, Koki Murakata and Satoshi Takahashi pointed out that the seller's low credit rating is one of the main reasons why consumers give up shopping on line[1]. According to the trading information on eBay, Standifird studied the influence of credit evaluation system on knock down price from the details in 2001. The research results showed that positive comments have a slight positive impact on the final auction price; however, negative comment has great negative impact. Each negative comment will decrease final transaction price by about $1 \%$, three or more negative comments will decrease final transaction price by $3.6 \%$. Negative comments lower down the seller's price [2]. Xing Xian (2010) found that the total number of

${ }^{*}$ Corresponding Author 
comments has an impact on consumers' purchasing decisions. The increasing number of consumers is consistent with the number of comments, that's to say, more product reviews bring more consumers, more consumers means more product reviews [3]. Zhao Ying and Cui Jin (2010) found that regular consumer believe in the brand products and its quality, who is not easily or rarely affected by the negative comments, however, for those half-and-half trust and uncertain consumer, customer comments has great influence on consumers' purchasing decisions, which would stimulate or stop them to purchase[4]. Huang Huiwen [5] and Huang Yan[6] hold that the current credit evaluation system is too simple, the comments is too subjective, and there are many fake comments which is difficult to identify, unreasonable aspects of credit evaluation system hindered the further development of e-commerce.

In summary, previous studies analyzed the effect of credit evaluation system mainly from the perspective of qualitative and statistics. In order to further the study of influence of credit evaluation system on online purchasing decisions, this paper takes China's largest B2C e-mall -TMALL as example, from the influencing factors of consumer behavior, to establish econometric model to study and analyze how the index set credit evaluation system affect consumer's decisions and put up advices for improvement of e-commerce credit evaluation system.

\section{The Influence-Mechanism of Internet Trading Credit Evaluation System}

\subsection{The Fundamental of Credit Evaluation System}

Owing to the vitality of e-commerce, businessman is likely to exaggerate the utility of their products on the web page to attract attention and to increase sales. It is difficult for consumers to recognize the products quality only through pictures and description. Therefore, consumers decide whether to buy through someone else's shopping experience which tells the quality of the products and the online-store credit.

The fundamental of credit evaluation system of online transactions: When the transactions are done, according to their own experience of the transaction, the buyers would make corresponding comments on the products within the time stipulated by the system, which eventually becomes the credit information of both buyer and seller. E-commerce platform would analyze the credit information feedback of all transactions through specific algorithm, which finally reflects basic credit of the sellers and provide reference for purchasing decisions of potential consumers. E-commerce credit evaluation system is a means for spread of credit information, which can reduce the mistrust of both sellers and buyers, transaction cost, and increase the probability of transactions.

\subsection{TMALL Transaction Credit Evaluation System}

TMALL plays a significant role in e-commerce transactions in China whose credit evaluation system is somewhat typical, which refers to grading instead of the "good", "medium", "bad" comments. Grading includes whether commodities are in conformity with description, the seller' service attitude, seller's delivery speed, logistics-delivery speed. TMALL online store grading system only manifests whether commodities are in conformity with description, the seller' service attitude, seller's delivery speed. In addition, TMALL also provides the level of store's marks in the same industry. TMALL's credit evaluation mechanism and the process are as follows:

(1)TMALL Commodity Evaluation Process. Buyers can make comments on the commodity after having used alipay to pay for the purchasing. Buyers can respectively give their marks whether commodities are in conformity with description, the seller' service attitude, seller's delivery speed, logistics-delivery speed. At the same time, the 
buyer can also make detailed comments on the quality of the products and service attitude and share their shopping experience or give the seller some suggestions. Once buyers submit the comments, it takes effect immediately and not be modified.

(2)TMALL Commodity Evaluation Mechanism. The website page of TMALL commodity evaluation system mainly includes three parts: marks on products being in conformity with description, popular tags, and comments' content. Grading module would manifest average of buyer's marks and display in the form of coordinate axes, such as, 4.5 means between "satisfaction" and "very satisfied". The frequent description of the products by the buyers would be summed up as a popular tags appearing on the evaluation-page, if users click on one of them, the system will automatically extract user's evaluation content containing the tags. Evaluation-content module is the main part of the commodity evaluation, which mainly manifests user's specific comments content, time, purchased products, user name, and user level. TMALL has added the function of the additional comments to improve the credit evaluation system. Buyers can again leave comments on the page within 90 days after the first evaluation of the products, and content of second comments cannot be modified, either.

\section{Model Establishment and Data Source}

\subsection{Model Establishment}

In order to study the influence of online transaction credit evaluation system on the online consumption decisions, the paper take monthly online sales as variable figure out whether cumulative sales affects consumers purchasing decisions, explanatory variables also include marking items of online transaction credit evaluation system, such as, marking of whether the products are in conformity with the description, service attitude, and delivery speed, the number of positive comments, the number of neutral comments and the number of negative comments. This paper adopts multiple linear regressions to make econometric analysis, and create model (1) as follows:

$$
Y=\alpha+\beta_{1} X_{1}+\beta_{2} X_{2}+\beta_{3} X_{3}+\beta_{4} X_{4}+\beta_{5} X_{5}+\beta_{6} X_{6}+\beta_{7} X_{7}+\varepsilon
$$

The $\alpha, \beta$ of model (1) are regression constant and partial regression coefficient. The $\varepsilon$ is the random error, it represents the changed parts of explained variable which is affected by other random factors. Explanation variable regression and explained variable of regression analysis are described in detail as Table 1:

Table 1. Variable Meaning Description

\begin{tabular}{ccc}
\hline Variable nature & Variable Name & Variable Meaning \\
\hline $\begin{array}{c}\text { Explained } \\
\text { variables }\end{array}$ & $Y$ & The sales within 30 days \\
& $X_{1}$ & The cumulative sales \\
& $X_{2}$ & Marks of coherence between the \\
& $X_{3}$ & products and descriptions \\
variables & $X_{4}$ & Marks of service attitude \\
& $X_{5}$ & Marks of delivery speed \\
& $X_{6}$ & The number of positive comments \\
& $X_{7}$ & The number of neutral comments \\
& & The number of negative comments \\
\hline
\end{tabular}




\subsection{Data Sources}

The number and effectiveness of samples are very important in the empirical analysis, this study need completely homogenous samples or same samples as much as possible, which to avoid to affect the results of the study because of the different products characteristics, only in this way can the paper effectively study the influence of accumulated sales, marks of products conformity with description, service attitude, delivery speed on recent following month. This paper selects Samsung S7562 mobile phone as a sample, because it is the mobile phone models which Samsung manufacturers designate, and the stocking sources are similar, which excludes the price difference caused by difference in products components. Search keywords "Samsung S7562 phone" on TMALL, you can get more than 200 results, which means there are more than 200 online stores selling the phone on TAMLL.COM. Owing to high sales of the mobile phone on TMALL, the number of transactions is also enough for data collection. This paper focuses on 30-day transactions of the Samsung S7562 from April 13, 2014 to May 14 , which is to collect the phone sales and several relevant variables information. At last, I got 5634 transactions information as valid samples from 54 sellers.

\section{Empirical Results Analysis}

\subsection{Correlation Analysis}

We should analyze the correlation between variables before the linear regression analysis to figure out the relationship between the variables. Correlation means when the value of a variable changes, the other variable also change accordingly, which is also the changing extent of variables caused by other variables.

Measuring of correlation is defined as coefficient of correlation, when the absolute value of correlation coefficient is greater than 0.8 , which means high correlation between the two variables; when the absolute value of correlation coefficient is less than 0.3 , which means no correlation between the two variables.

Table 2. Correlation Analysis between Variables

\begin{tabular}{ccccccc}
\hline & $Y$ & $X_{1}$ & $X_{\mathrm{m}}$ & $X_{2}$ & $X_{3}$ & $X_{4}$ \\
\hline$Y$ & 1 & 0.872059 & 0.894287 & -0.05464 & -0.06925 & -0.17652 \\
$X_{1}$ & & 1 & 0.997952 & -0.06361 & -0.10037 & -0.17652 \\
$X_{\mathrm{m}}$ & & & 1 & -0.06473 & -0.0943 & -0.17365 \\
$X_{2}$ & & & & 1 & 0.825968 & 0.710846 \\
$X_{3}$ & & & & & 1 & 0.838413 \\
$X_{4}$ & & & & & & 1 \\
\hline
\end{tabular}

In Table 2, $X_{\mathrm{m}}$ is the total of the comments, whose value is the sum of the positive comments, negative comments and neutral comments within in a month. Correlation analysis results show that the correlation coefficient between cumulative sales or comments and sales of following month is more than 0.8 , which obviously means strong correlation between sales of following month, accumulative sales, and the total comments; however, the correlation coefficient between three marking of the three items and sales of following month is less than 0.3. In other words, there is no obvious correlation between marking of service attitude, marking delivery speed and sales of following month. 


\subsection{Linear Regression}

According to the collected data, this paper adopts software E-views to apply multiple linear regressions to model 1, the result is as the following in Table 3: (1) When the $\mathrm{R}$-squared is 0.7973 , this means that in mutation of the explained variable, $79.73 \%$ were caused by the explained variables; (2) When the statistical magnitude F is less than 0.05 , which means the linear relationship between the whole explanatory variables and the explained variables is obvious; (3) In explanatory variables, test value $t$ of the cumulative sales, the number of the positive, neutral and negative comments, are all greater than 2.00 , $t_{0.025}(50)=2.009$, which means the four explanatory variables have obvious influence on sales of the following month; (4) The parameter of the cumulative sales and neutral comments is positive number, which means the cumulative sales and the neutral comments have obvious influence on sales of following month; (5) The parameter of the positive comments and negative comments is negative number, which means the positive comments and negative comments have native influence on sales of following month; (6) The statistical magnitude value $\mathrm{P}$ of coherence between the products and descriptions, service attitude and delivery speed are all far greater than the significance level $\alpha=0.5$, which means marking of the three items has little influence sales of following month; (7) In Table 3, the DW value is 2.3393 which between 1.5 and 2.5 , that is to say there exists no autocorrelation in residual error-sequence. Therefore, the regression equation can reflect characteristics and changes law of the explained variable.

Table 3. Linear Regression Results

\begin{tabular}{|c|c|c|c|c|}
\hline Variable & $\begin{array}{c}\text { Parameter } \\
\text { estimates }\end{array}$ & $\begin{array}{l}\text { Standard } \\
\text { deviation }\end{array}$ & Test value & Value $\mathrm{P}$ \\
\hline$\alpha$ & 748.0142 & 1247.511 & 0.599605 & 0.5518 \\
\hline$X_{1}$ & 0.148086 & 0.019864 & 7.454805 & 0.0000 \\
\hline$X_{2}$ & -52.89419 & 409.9219 & -0.129035 & 0.8979 \\
\hline$X_{3}$ & 516.8437 & 520.0574 & 0.993820 & 0.3256 \\
\hline$X_{4}$ & -573.5298 & 444.4021 & -1.290565 & 0.2034 \\
\hline$X_{5}$ & -6.318286 & 2.929167 & -2.157025 & 0.0364 \\
\hline$X_{6}$ & 19.92164 & 8.351103 & 2.385510 & 0.0213 \\
\hline$X_{7}$ & -30.40916 & 13.92826 & -2.183270 & 0.0343 \\
\hline$@$ TREND () & -4.977368 & 3.736712 & -1.332018 & 0.1896 \\
\hline R-squared & 0.797328 & \multirow{7}{*}{\multicolumn{2}{|c|}{$\begin{array}{l}\text { Mean dependent var } \\
\text { S.D. dependent var } \\
\text { Akaike info criterion } \\
\text { Schwarz criterion } \\
\text { Hannan-Quinn criter. } \\
\text { Durbin-Watson stat }\end{array}$}} & 104.3333 \\
\hline Adjusted R-squared & 0.761297 & & & 317.6070 \\
\hline S.E. of regression & 155.1739 & & & 13.07798 \\
\hline Sum squared resid & 1083552. & & & 13.40948 \\
\hline Log likelihood & -344.1055 & & & 13.20583 \\
\hline F-statistic & 22.12919 & & & 2.339251 \\
\hline Prob(F-statistic) & 0.000000 & & & \\
\hline
\end{tabular}

\subsection{The Result Analysis}

According to Table 3, we can draw the following conclusions after further analysis:

(1)Cumulative sales have a significant influence on sales of flowing month. The research results show that the cumulative sales have a significant influence on sales of flowing month. First of all, the total sales is a good reflection of the seller's credit, consumers won't buy the products sellers of bad reputation. Second, the commodity comments brought by the accumulative sales provide a good reference for consumers, 
because consumers can get more information about the products, seller's information and logistics information from so many comments. If there is only a few comments of "very good", "not bad" a commodity, then the comments are of little referential value. It is difficult for consumers to find information which they are interested in and they may choose another online store.

(2)More positive and negative comments have a negative influence on the sales of the following month. Linear regression results indicate that more positive and negative comments have a negative effect on sales of the following month. In general, positive comments is benefit for following month's sales, however, with the advent of credit-forging phenomenon, for consumers, positive comments is of little referential value. A group of survey data of British shopping evaluation website Reevoo shows, $68 \%$ of online shopper will believe more in positive comments if there are few negative comments, however, $95 \%$ them said they would be suspect of positive comments if they can't see a bad comment praise, which is likely to persuade consumers out of purchasing, what's more, real stores are more reliable to customers. Second, content of positive comments is too monotonous, which leads to lack of commodity information, seller's information, and a detailed description of the logistics information, in this case, the referential value of positive comments is greatly decreased. Consumers can't find the valuable information in these positive comments so that it is difficult to make a purchasing decision; linear regression analysis results show that negative comments have negative influence on sales the following month. Negative comments of consumers mainly include dissatisfaction of the product quality, sales service attitude, logistics delivery speed and the service attitude. These negative comments can persuade consumer out of purchasing for bad feeling to product or store.

(3)Neutral comments have positive an influence on the sales of following month. The neutral comments of the products have difference with negative comments; those buyers who neutral comments are mostly not satisfied with small aspects, such as slow seller's delivery speed, slow logistics-delivery speed and other small flaws, which only show consumers dissatisfaction with small aspects instead of purchasing process. If there is no problem with product quality and business services, the number of neutral comments will stay in a reasonable proportion, because few consumers would give a neutral comment without any reasons. For sane consumers, these small problems is not enough to affects their purchasing decision, instead, which embodies the authenticity of comments content, to a certain extent, so neutral comments would stimulate the consumers to buy.

(4)There is no correlation between the store's three dynamic scoring and the sales of following month. Research results analysis shows, marking of whether commodities are in conformity with description, the seller' service attitude, seller's delivery speed, and logistics-delivery speed have little influence on the sales of the following month. Three store's dynamic scoring reflects the overall impression previous consumers on product quality, service attitude and delivery speed, however, which cannot give consumers specific reference information. We can see from the extracted samples that the all stores have little difference in marks of the three aspects; they all get high scores, so it's difficult for consumers to judge the store's credit according to the three marks.

\section{Suggestions and Countermeasures}

Based on the above analysis, online transaction credit evaluation has some influence on online purchasing decisions; consumers will make reference to previous comments and decide whether to buy. Therefore, this paper gives following suggestions to establish credit evaluation system of e-commerce platform:

(1)Strengthen the real-name identification. Since the cumulative sales have obvious influence on sales of following month, both buyers and sellers pay great attention to 
commodity sales, which is why online seller forges transactions records to improve the credit. To reduce transactions records false, E-commerce website should strictly examine seller's applications for registration, strengthen identity-certification and real-name identification, developing detection system of real-name identification, which is to protect the benefits of consumers.

(2)Evaluation system should figure out the similar comments so that buyer can read comments more efficiently. The number of positive comments and negative comments has influence sales of following month, and most positive feedbacks don't refer to details, there is little detailed and complete description about the products, which makes the referential value of positive comments lower than that of neutral comments. At the same time, because of the phenomenon of credit speculation, it is difficult for consumers to judge the authenticity of the comments. To solve this problem, the E-commerce website can provide filtration of same comments; potential buyers can more effectively know the experience of the previous customers, buyers of the user experience, which also enhance authenticity of comments.

(3)Set up evaluation-reference tags. For potential buyers, whether commodity comments are detailed has some influence on customer purchasing decisions. E-commerce website can increase the tags of product-attribute, set different keywords for different products, which is to guide consumers to make detailed comments according to the keywords.

Online sellers should pay attention to the authentic comments of buyers, even if the assessments are neutral, which also has greater influence on consumers than that of the positive ones. The study of this paper again proves that falsified transaction records and false positive comments obtained through other ways have little significance in promoting the sales.

\section{References}

[1] M. Tokuro, M. Koki and T Satosh, "Effects of Computational Mechanism Design in User Evaluation System Anchorage", Proceedings of the IEEE International Conference on Systems, Man and Cybernetics, Alaska, (2001).

[2] S.S. Stephen, "Reputation and E-commerce: eBay Auctions and the Asymmetrical Impact of Positive and Negative Ratings", Journal of Management, vol. 7, no. 2, (2001), pp.279-295.

[3] X. Xian, "The Impact of Evaluation System on Consumer Behavior Customer under the B2C Mode", China Business, vol. 5, (2010), pp.40-43.

[4] Z. Ying and C. Jing, "The Influence of Online Shopping Comments on Online Consumption", Technology and Information, vol.32, (2010), pp.264-265.

[5] H. Huiwen, "An Study on C2C Online Shopping Credit Mechanism", Economic and Social Development, no.7, (2009), pp.85-88.

[6] H. Yan, K. Chuwen and G. Wenting, “An Study On Taobao's credit rating”, Friends of science, no.12, (2009), pp.66-68. 
International Journal of Multimedia and Ubiquitous Engineering

Vol. 12, No. 5 (2017) 